\title{
THEORETICAL CONSIDERATIONS REGARDING VIRTUAL METHODS TO OBTAIN THE GARMENT PROTOTYPE (2D/3D AND 3D/2D)
}

\section{DOI: $10.35530 /$ TT.2021.47}

\author{
M. Avadanei ${ }^{1 *}$, A. Talpa ${ }^{2}$, A. Curteza ${ }^{1}$, D. Viziteu $^{1}$, I. Dulgheriu ${ }^{1}$ \\ ${ }^{1}$ Faculty of Industrial Design and Business Management, "Gheorghe Asachi” Technical \\ University of Iasi-Romania \\ (E-mail: mavad@tex.tuiasi.ro,_acurteza@gmail.com, viziteudianaroxana@gmail.com, \\ ionut.dulgheriu@yahoo.com) \\ ${ }^{2}$ SC Katty Fashion Company SRL, Romania \\ (E-mail: talpa.andreea@yahoo.com)
}

\begin{abstract}
With the progress and development of science and technology, virtual reality technology is becoming more and more present, its application in digital creations is becoming more and more widespread. Everything the user does is calculated by the computer and has real-time feedback, making this virtual environment more realistic and giving the user an immersive experience. This technology integrates the latest developments in computer science, computer simulation, artificial intelligence, recognition, display and online parallel processing. Virtual prototyping offers a new way to explore the design and subsequent changes that need to be made to the product before it is manufactured in larger quantities or put into production. The development of new product models using virtual tools requires a certain level of training of the designer; he/she must have skills in understanding and using the specific tools for CAD systems (2D and $3 D$ ) and technical knowledge regarding the ways of conceptual product development. This paper presents the methodology of the virtual development process for an apparel product model, using the tools of the $2 D$ and $3 D$ digital environments. The first solution is to design the $2 D$ patterns of the components of an apparel product, followed by a $3 D$ simulation that verifies the aforementioned solution. The second solution is to design the 3D components using the tools of the 3D digital environment (the software used is Clo3D) and then extract the $2 D$ parts required for the classical manufacturing process.
\end{abstract}

Keywords: digitalisation, virtual prototype, 2D patterns, 3D simulation

\section{DIGITALISATION-THE NEW REALITY}

Digitalisation is regarded as a major phenomenon that has drastically changed society. Technological advancement ensures a better quality of life, as well as social evolution. Digital technology lies at the forefront of technological development, and its effects are felt in all economic and social sectors [1].

A report from early 2021 shows that the number of people that use internet for socialising, communication, professional activities, product/service acquisition is currently increasing [2].

Even though 3D technology has been used in engineering fields for many years (furniture industry, automotive, aerospace, etc.), it has been used in the apparel industry for a relatively short period of time. This kind of technology comes with a whole range of advantages. It can be used at every stage of the product development process, from design 
and sampling, as well as for 3D images and videos for product website pages or fashion shows (figure 1 ).

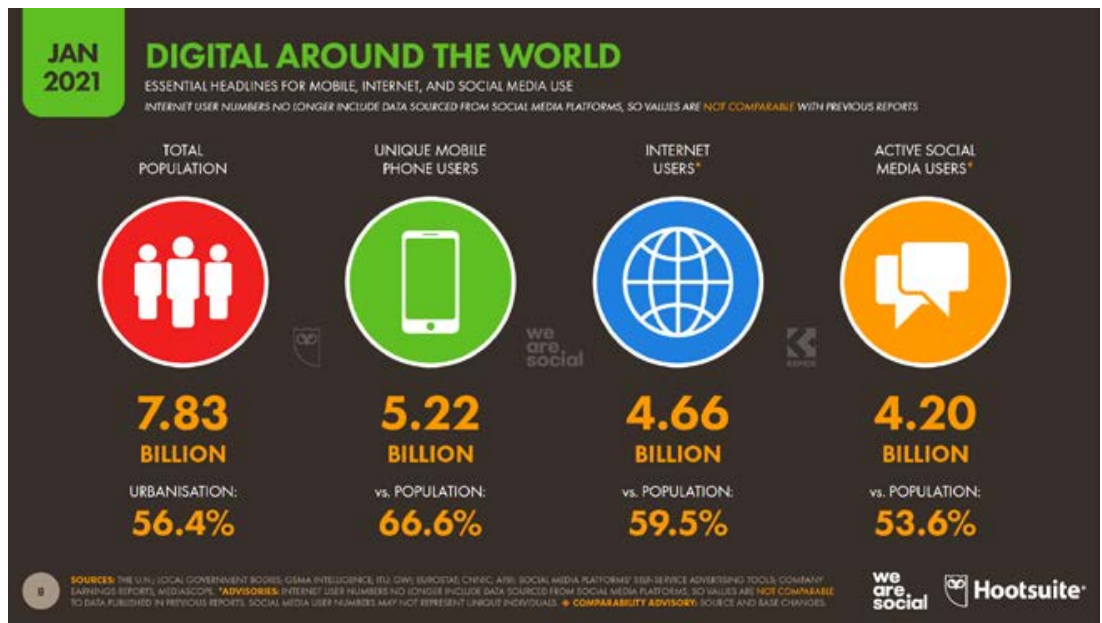

Figure 1. Digital Around The World - Ian 2021[2]

Virtual prototypes provide the designer with new methods of creating products and of simulating what they will be like in reality, before being physically manufactured.

The development of 3D technologies has a positive impact on the field of consumer goods. This kind of technology provides the environment and tools that are necessary in order to simulate the desired product in a virtual space. At the same time, it allows the user to validate the design solution, and to cut down on production costs, energy consumption, pollutants, labour, thus making the design process sustainable [3,4].

The paper presents the main steps of the virtual development process for an apparel product model, which uses the tools provided by 2D and 3D digital environments:

- Designing the 2D patterns of the components of a garment product, followed by a 3D simulation which verifies the aforementioned solution;

- Constructing the 3D components by using the tools of the 3D digital environment (the software that has been used is Clo3D) and then obtaining the 2D pieces which necessary for the classic manufacturing process.

\section{VIRTUAL METHODS OF DESIGNING GARMENTS}

Digitalisation boils down to "the transformation of interactions, communications, relationships, business functions, and business models into multiple digital processes, often reduced to a combination of digital and physical processes. Digitalisation involves the use of digitised information (or information directly received in a digital format) [3].

Increasingly many apparel companies are using digital tools, and this comes with several advantages:

- the reduction of the time that is necessary to produce the first prototype,

- a significant reduction of the manufacturing costs,

- the reduction of waste,

- the possibility of making changes in real time, and of viewing them,

- the possibility of diversifying the model - by combining or altering the textures of materials,

- the possibility of co-creation service,

- improved communication between the development and production departments, 
- online promotion of the created model.

The digital approach to the virtual development of apparel product models can be implemented in two ways:

-a 2D design process of the product components, followed by a 3D simulation on the corresponding virtual mannequin;

-a 3D design process that is directly carried out on the mannequin, followed by the extraction of the 2D patterns that are necessary for the manufacturing process of the selected model.

In CAD applications based on the first type of approach (from 2D $\rightarrow 3 \mathrm{D}$ ), one edits the shape of the components are performed in the 2D module, and then proceeds to the 3D simulation stage. 3D simulations enable one to visualise the behaviour of the materials in the final product (in this way, one can verify that they have been chosen in accordance with the model and the intended purpose).

In applications based on 3D design, one makes the changes in the design area (3D), and then extracts the 2D shapes of the parts (if the product is made with classical technology, the sewing). The 3D shape of the model (if one can be created) can be exported to a 3D printer in order to obtain the desired product.

The two methods of virtual development of the clothing product models are illustrated for a product with shoulder support (woman dress). The model has both symmetrical and asymmetrical markings, as well as division lines at the top for adjusting and volume at the bottom. The sleeve of the product is fitted with a cuff at the end (figure 2).
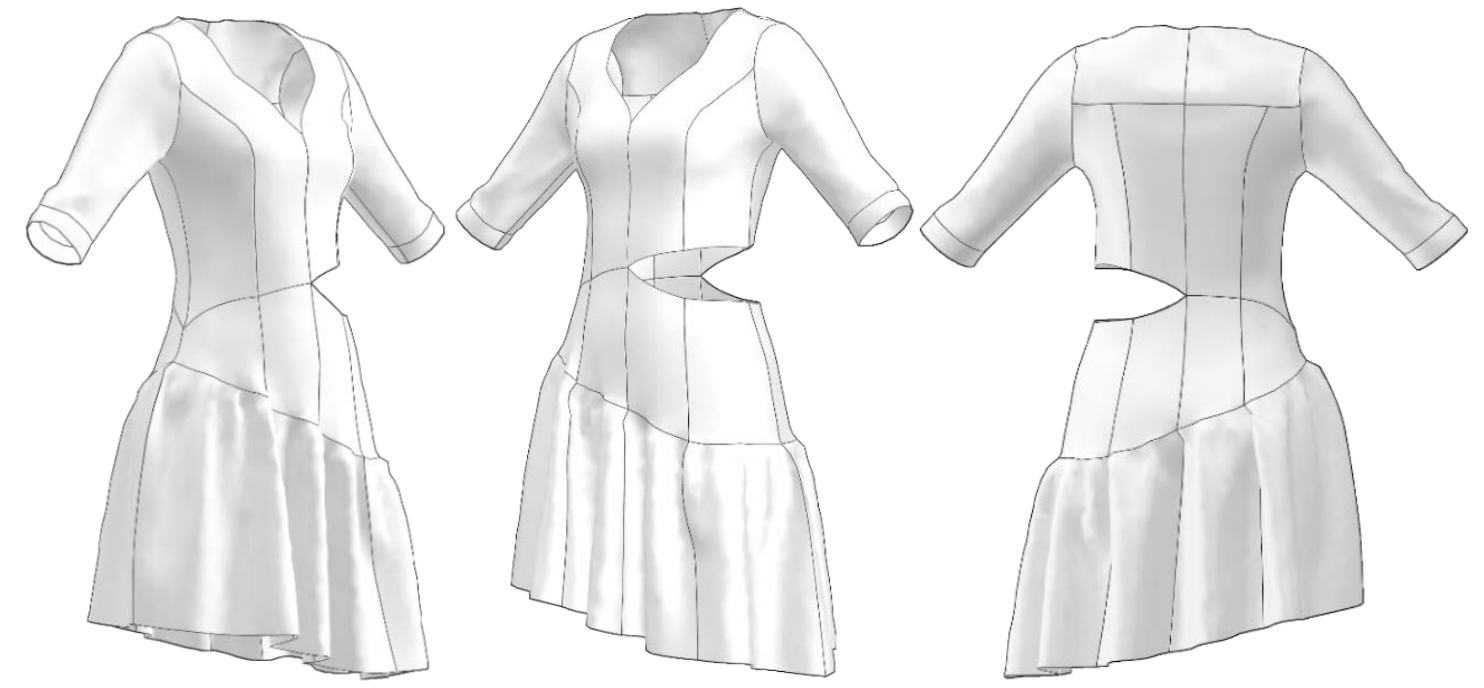

Figure 2. Model sketch

\section{simulation \\ 2.1. Designing the model in $2 \mathrm{D}$ and validating the resulting prototype via $3 \mathrm{D}$}

Manufacturers of software for the clothing sector have developed software packages that allow an individualised / customised design of the patterns (Lectra, Gemini, Graphis, etc.) that takes into account the constructive aesthetic characteristics of the model and the physical characteristics of the wearer (conformation, proportions). For the selected model, the 2D design process of its components was carried out using the MTM module of the Gemini CAD system. In this design environment, depending on the chosen solution, the user picks certain initial data and processes certain mathematical relations in order to decide upon the dimensions of the components of the product. The structure of the initial data or of 
the mathematical relations can be changed very easily depending on the requirements for the model/component. The design process of the shapes of the product components is carried. out in a layer called the geometric layer. If the product components are still linked with the geometrical layer in which the design was made, then any change in the size, volume and values of the initial data, or in the structure of mathematical relations determine the alteration of the product elements (figures 3, 4 and 5) [5,6].

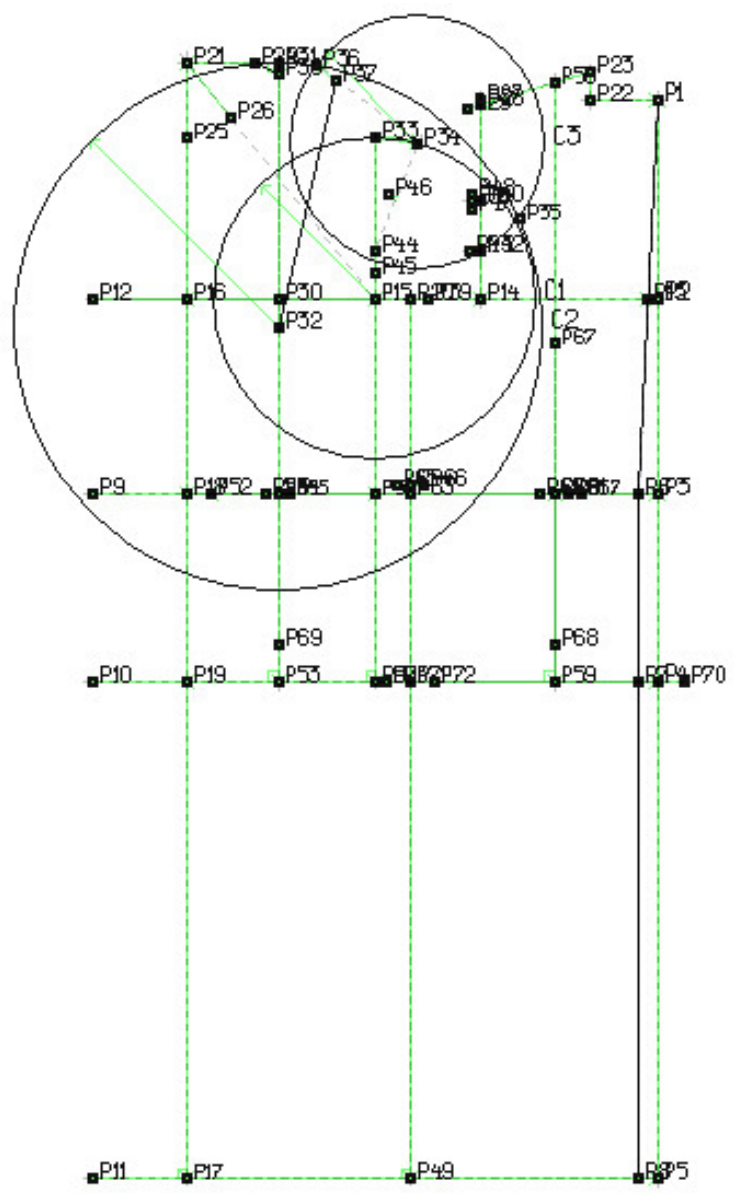

Figure 3. The network for the main elements (front and back)

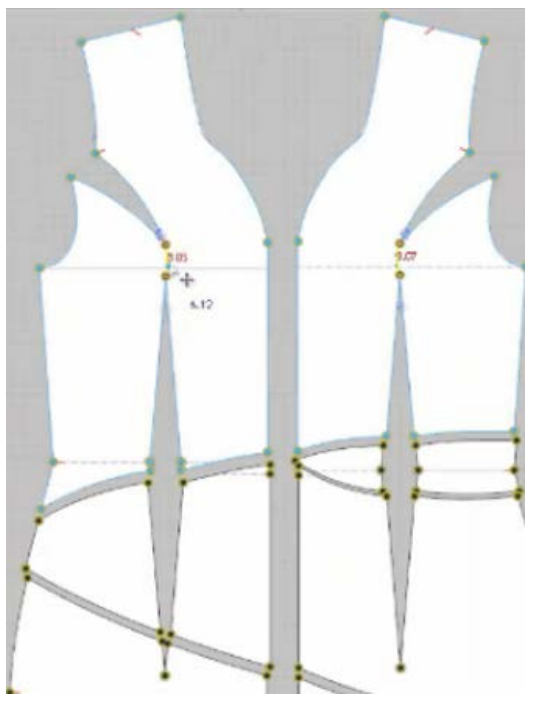

Figure 4. The front model pieces

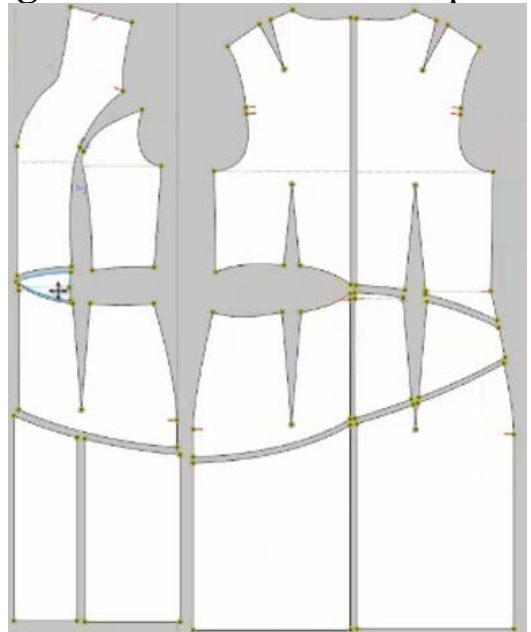

Figure 5. The back model pieces

After obtaining the shape of the components of the model, we proceed to the 3D simulation, which is performed in Clo3D $[7,8]$. In the simulation process, one takes into account the physical and mechanical properties of the materials, the manufacturing technology and a mannequin corresponding to the one used in the 2D design stage.

The simulation process consists of:

- selecting the avatar (the mannequin), choosing an appropriate shape and dimensions (size and posture), and scaling the mannequin until they are achieved. The values of body dimensions are similar with the one which were used in the design scenario (personalised);

- placing the pieces near the avatar;

- declaring the assembly lines; 
- selecting the material (basic, since it is a single product);

- simulating the sewing process, and checking the length of the assembly lines (figures 6, 7, 8 and 9).

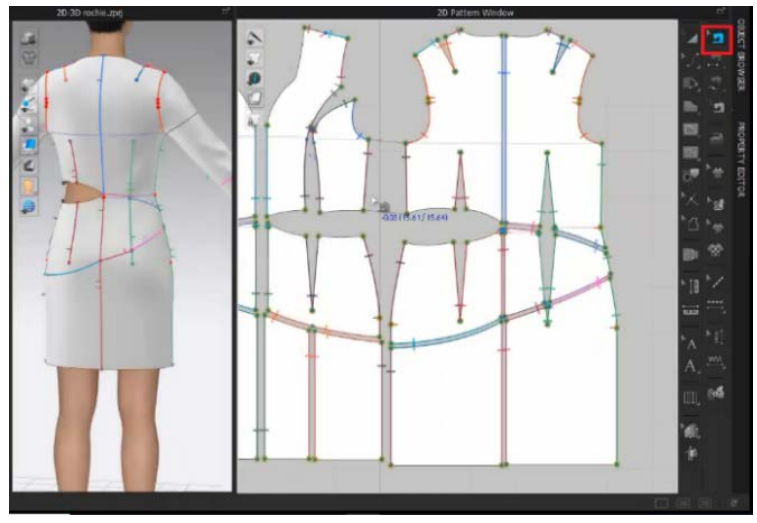

Figure 6. Checking the length of the sewing lines

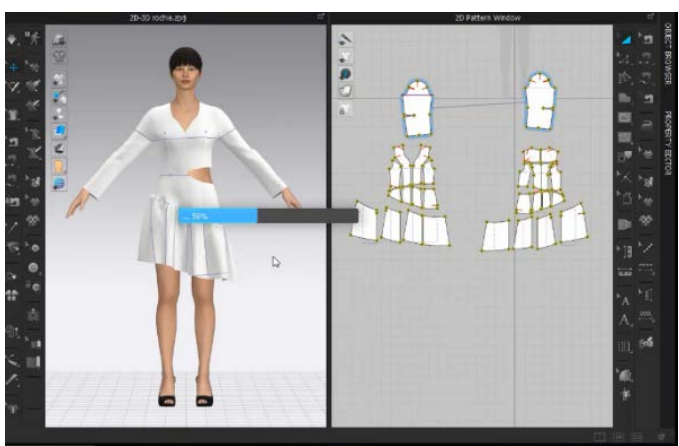

Figure 8. Product simulation- checking the distribution of the fullness

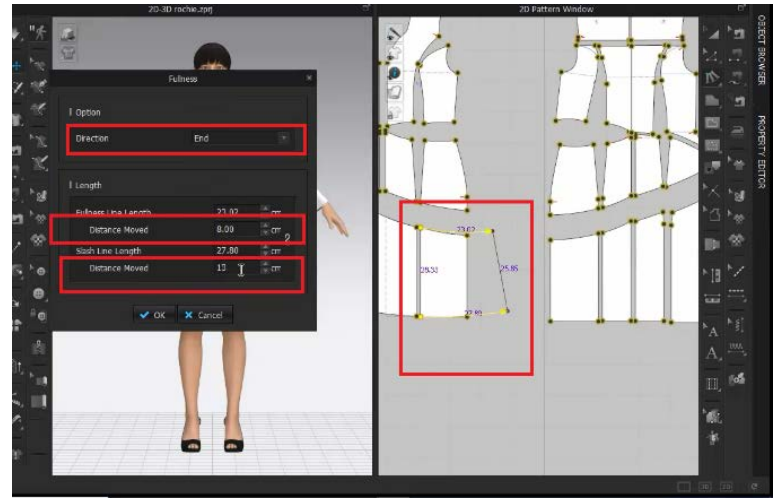

Figure 7. Establish the orientation of the fullness

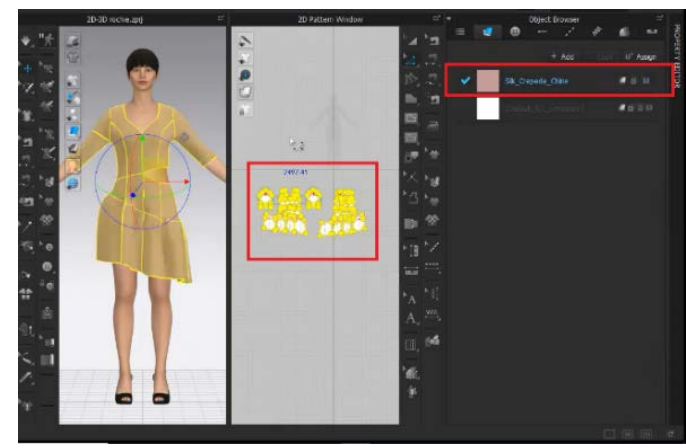

Figure 9. 3D final model (virtual representation)

During the simulation process, if the designer finds problems with the fit and position of the product on the avatar, he will return to the previous phase (2D design phase) and make the necessary changes to eliminate the problems. He will run the 3D simulation process again to be sure that the problems have been solved (figure 10).

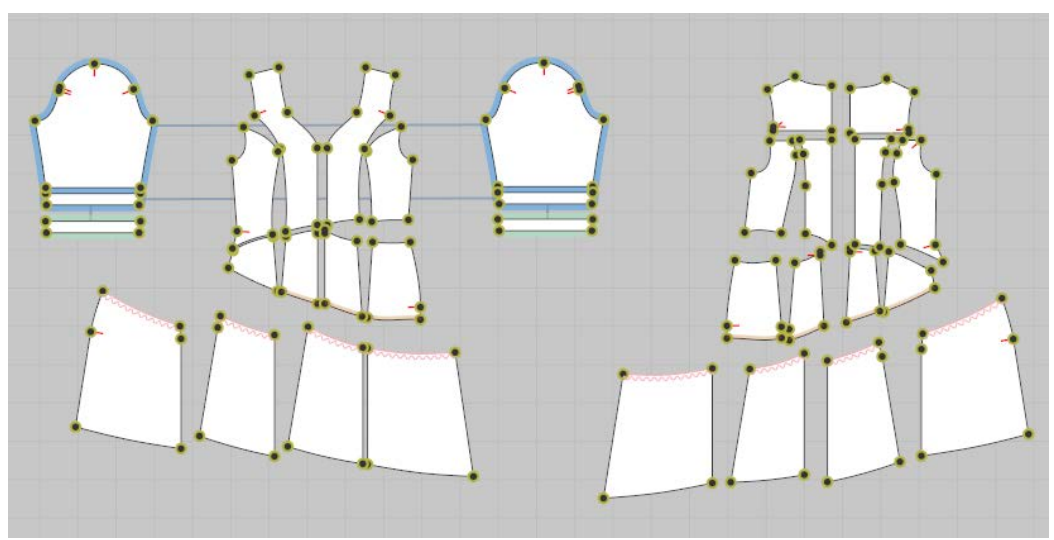

Figure 10. 2D model pieces 


\subsection{Directly designing the product on the avatar in a $3 D$ virtual environment.}

Obtaining the corresponding $2 \mathrm{D}$ patterns.

The direct 3D design of the product on the virtual mannequin requires knowledge and skills pertaining to the steps that are used in order to obtain the product components, physiochemical properties of textiles, expertise in anthropometry (static and dynamic regime), and in the usage of the tools provided by CAD systems. In order to obtain the shape of the component, the designer needs to know what they want to achieve, the logical and necessary steps for drawing the contour lines (model lines), the relationship between the product components and their support surfaces, and the contour, control and magnetisation points between the product and the body [9-11].

The designer selects the tools that are needed in order to draw the shape of the product component. The direct 3D dimensioning of the latter takes the silhouette and the details of the model into account.

Before the 3D design phase, the designer analyses the silhouette of the model, evaluates the additions that are necessary in order to maintain the silhouette, and takes these details into account when drawing the product components on the avatar (figures 11-19) $[5,7,8]$.

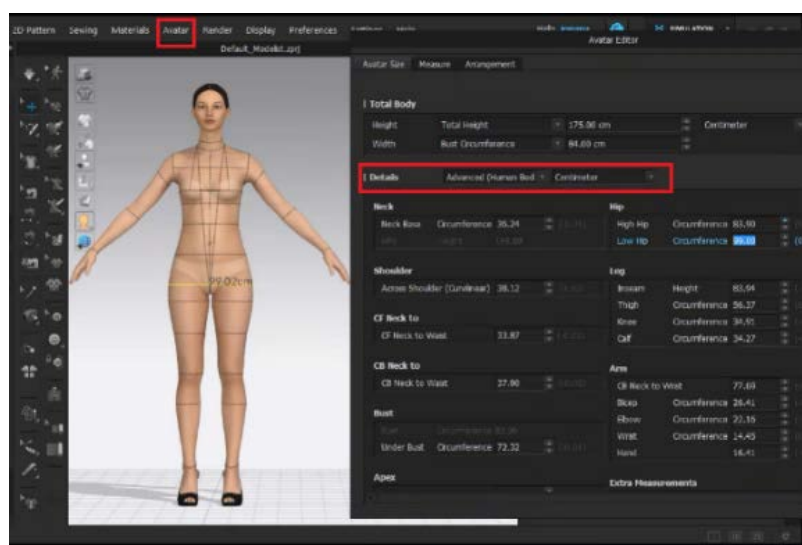

Figure 11. Change the avatar dimensions and position

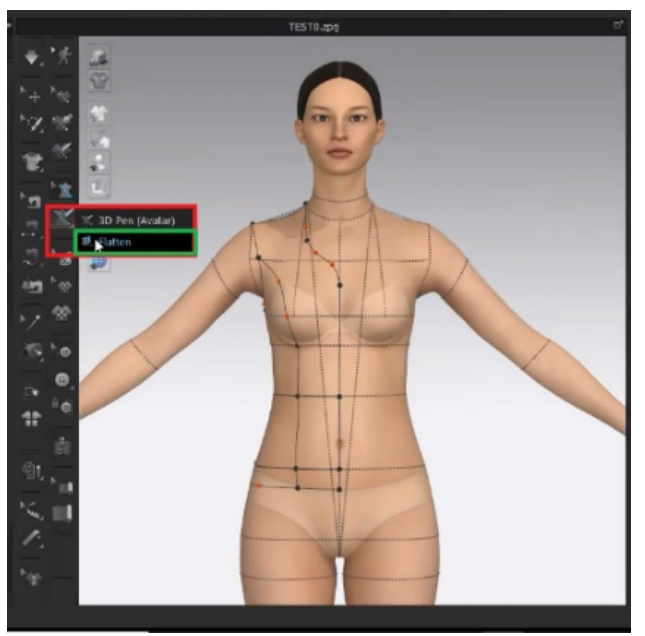

Figure 13. Preparation of piece extraction

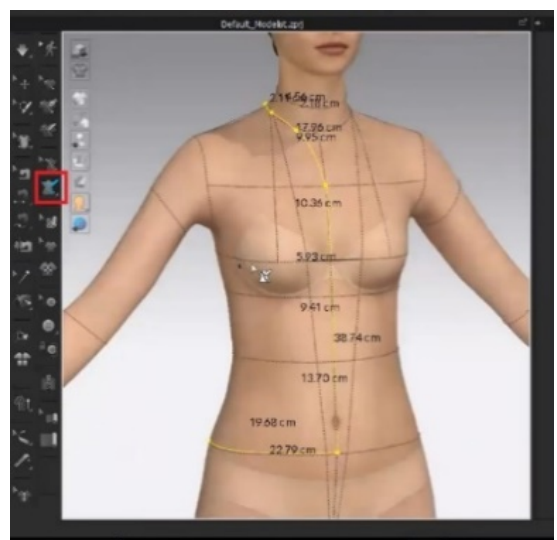

Figure 12. Draw the model lines linked with specific points on the avatar

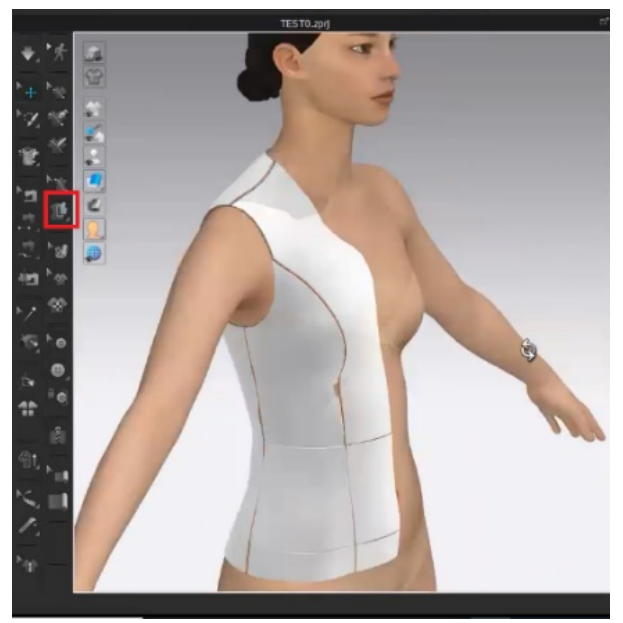

Figure 14. Model pieces (bodice pieces) 


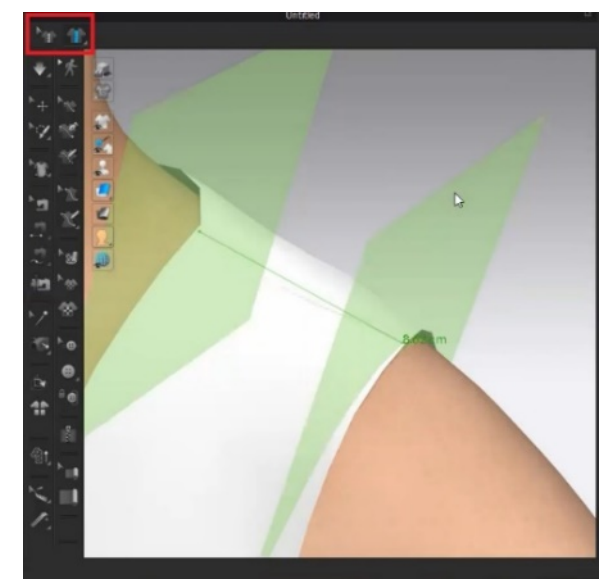

Figure 15. Checking the model dimensions (the length of the shoulder line)

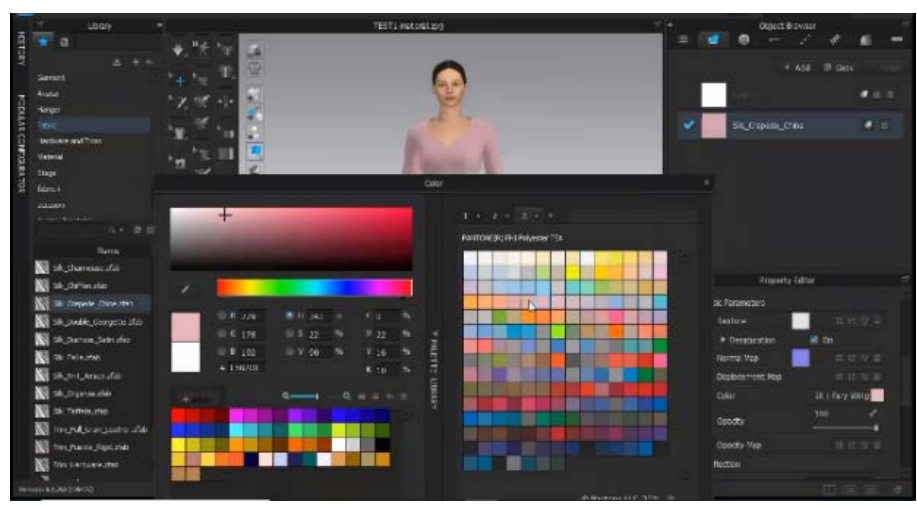

Figure 17. Material selection

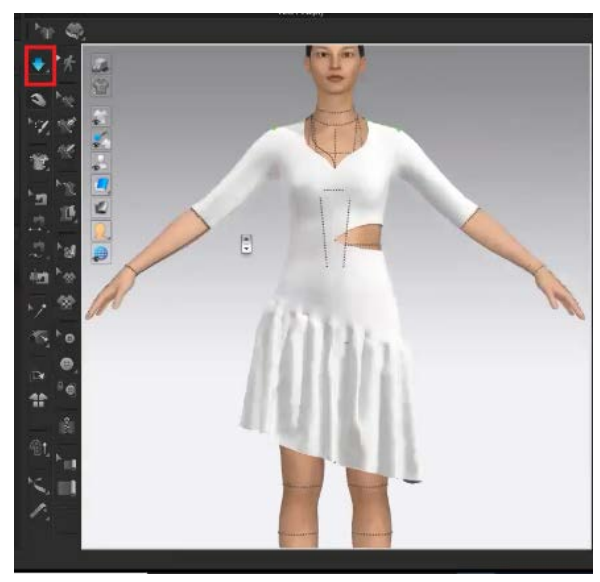

Figure 16. Product simulation

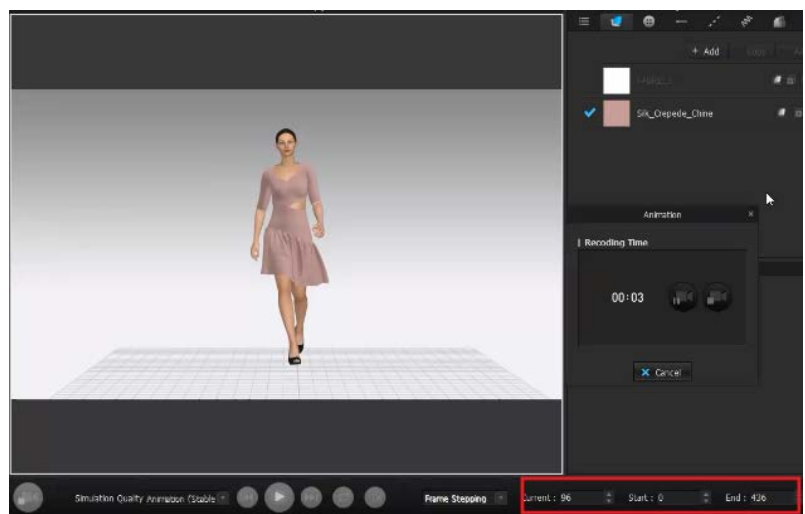

Figure 18. Avatar movement

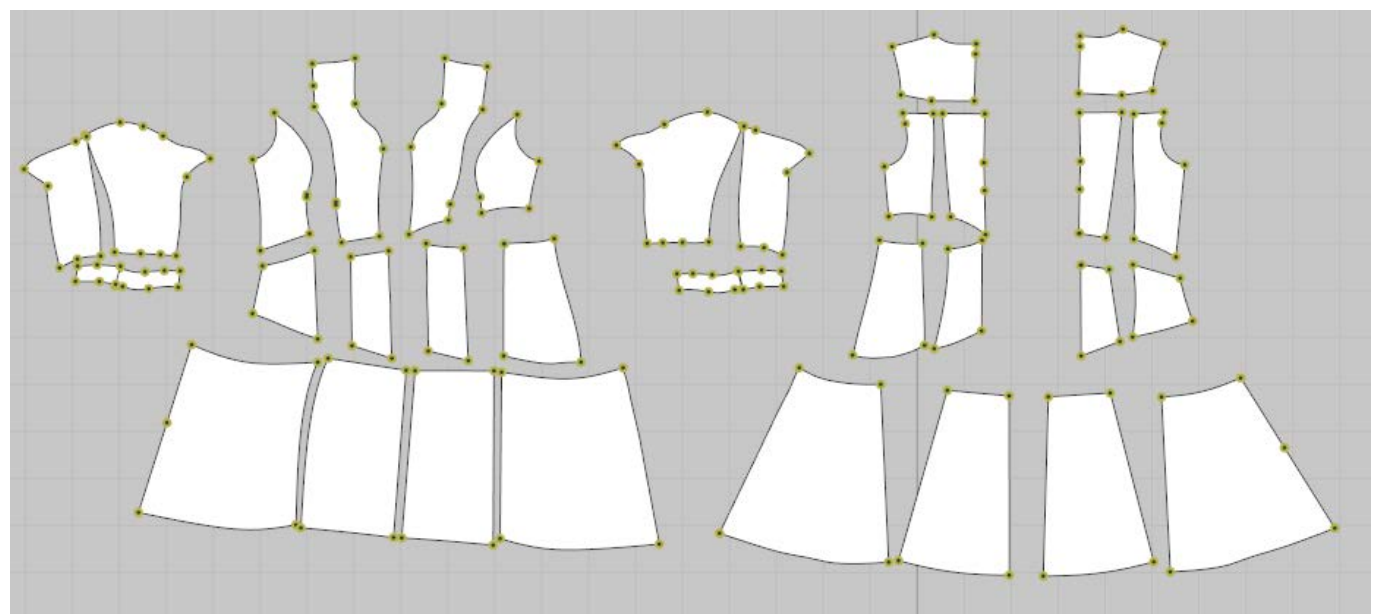

Figure 19. The model pieces (design 3D and exported in 2D)

\section{RESULTS AND DISCUSSIONS}

By analysing the shapes of the model components obtained by using the two aforementioned methods, one can notice certain differences in the geometry of the contour lines and of their surface. The shape and geometry of the contour lines drawn directly on the 3D avatar depend on the following factors: the complexity of the model, the anatomical 
characteristics of the mannequin, the experience of the user in identifying and defining the position of the magnetisation/pinning points of the components of the avatar, and in choosing the right methods of technical modelling for the surface of some parts (volumes), in order to obtain the desired model.

The modelling in the 2D work mode is done by using decorative-constructive lines, while in the 3D work version the same process is carried out automatically by extracting the pieces drawn on the avatar. The shape of the latter is then altered according to the one of the body. In order to obtain their correct shape, the designer must take the following into account: the details of the model, the necessary technical means, the position of the body of the avatar and the physical and mechanical properties of the materials.

In the 2D work mode, after having decided upon a type of material (depending on the elasticity level of the material), the shape of the contour line of every component will have to be adapted to the shape of the body during the 3D simulation process, depending on the elasticity of the material (in the landmark, it remains a straight line). If you draw the pattern directly on the avatar (direct 3D construction), its shape is going to imitate the one of the corresponding area of the avatar. After having extracted the corresponding 2D pattern, the shape of the contour lines will have to be adjusted depending on the type and model of the product.

In the direct 3D design scenario for dimensionally stable products (multilayers), the one must take consider the thickness of the layers of the components, the number of intermediate layers, the extra material between the layers, and the physical and mechanical interactions between them and with the intermediates the avatar.

\section{CONCLUSIONS}

The whole process of pattern design is increasingly carried out by software programs that enable one to visualise the resulting components in a virtual environment.

The designer that wishes to employ the direct 3D design method must take into account the constructive-aesthetic characteristics of the model, the aesthetic and technological impact of the material, the manufacturing technology, and the characteristics of the wearer's body in terms of posture or conformation. Knowing this information enables one to obtain a product that meets the requirements specified in the technical documentation (by the customer).

In summary, digital transformation comes with costs, efforts and risks. It is crucial to keep up with the global technological evolution and to remain competitive.

Investing in digitalisation and training employees in using specialised software for their tasks should be a top priority for both business owners and managers. At the same time, everyone should be provided with resources that enable them to adapt to the digital age.

\section{REFERENCES}

[1] Knell, M., The digital revolution and digitalised network society, Springer Link, 2021, Available at: https://link.springer.com/article/10.1007/s43253-021-00037-4 [Accessed on June 2021]

[2] Kemp, S., DataReportal, 2021, Available at: https://datareportal.com/reports/digital-2021-globaloverview-report [Accessed on June 2021]

[3] Yuwei, M., Mok, P.Y, et al., Computer aided clothing pattern design with 3D editing and pattern alteration, Available at: https://www.sciencedirect.com/science/article/abs/pii/S001044851200067X [Accessed on June 2021] 
[4] Avadanei, M., Olaru, S., Ionescu, I., Ursache, M., Ciobanu, L., Alexa, L., Luca, A., Olmos, M., Aslanidis, T., Belakova, D., Silva, C., ICT new tools for a sustainable textile and clothing industry, In: Industria Textila, 2020, 71, 5, 504-512, http://doi.org/10.35530/IT.071.05.1811

[5] M. Avădanei, Principii de construcţie şi modelare ale produselor vestimentare, Iași: Casa de Editura Venus, 2005

[6] Gemini Cad, Available at: http://www.geminicad.com_[Accessed on June 2021]

[7] C. 3D, 2021, Available at: https://www.clo3d.com/ [Accessed on June 2021]

[8] Clo3D, Available at: http://www.clo3d.com [Accessed on June 2021]

[9] Olaru, S., Filipescu, E., Filipescu, E., Niculescu, C., Salistean, A., Software solution to assess morphological body through 3D scanning results, In: Proceeding of the 9th International Scientific Conference eLearning and software for Education Bucharest, April 25-26, 2013, 3, 391-398

[10] Özbek, A., Online customized T-shirt design and evaluation of online websites for customization, In: Industria Textila, 2020, 71, 4, 371-379, http://doi.org/10.35530/IT.071.04.1674

[11] Dimitrijević, D., Spaić, O., Đurić, Ž., Urošević, S., Nikolić, M., CAD/CAM system implementation criteria in the process generating of optimal and efficient models for clothing industry, In: Industria Textila, 2020, 71, 5, 467-472, http://doi.org/10.35530/IT.071.05.1741 